\title{
Contextual Effects of Ethnicity, Gender, and Place on Depression; Case Study of War Related Stress for Kurdish Women
}

\author{
Shervin Assari ${ }^{1,2,}$, Valerie Micol-Foster ${ }^{1}$, Masoumeh Dejman ${ }^{3}$, Ali Ayoubian ${ }^{4}$, Maryam Moghani Lankarani ${ }^{1}$ \\ 1. Department of Psychiatry, University of Michigan School of Medicine, Ann Arbor, USA \\ 2. Center for Research on Ethnicity, Culture and Health (CRECH), School of Public Health, University of Michigan, Ann Arbor, USA \\ 3. Department of Mental Health, Bloomberg School of Public Health, Johns Hopkins University, Baltimore, USA \\ 4. Health Research Center, Baqiyatallah University of Medical Sciences, Tehran, Iran
}

*Corresponding Author: Shervin Assari, MD, MPH, Department of Psychiatry, University of Michigan, 4250 Plymouth Rd., Ann Arbor, MI 48109-2700. Tell: 734- 363-2678, Fax: 734-615-8739

Email: assari@umich.edu

\begin{abstract}
Contextual factors such as ethnicity, gender, place, and their intersections determine the social condition that populations and individuals live in. As a result, environmental stressors that shape exposures, and also resilience and vulnerabilities are specific to the population. This emphasizes the role of the intersection of such contextual factors in studying psychosocial causes of depression. The aim of this case study is to review the role of war related stress as a unique environmental cause of depression among Kurdish women who live in the Middle East. First, we reviewed the literature on the direct effects of ethnicity, gender, place, and their intersections on depression. Then we discussed the contextual (indirect) effects of these factors in modifying the effect of (resilience and vulnerability to) risk factors of depression. Then we reviewed the evidence highlighting the role of war related stress as a unique social cause of depression among Kurd women. We hope this paper provides an example of how social causes of depression depend on intersections of ethnicity, gender, and place. We argue that depression should be seen as a condition, with population specific causes and consequences. We also believe that ethnicity, gender, and place help clinicians and public health officials to better approach depression within populations. Contextual factors should not be undermined in approaching depression across population groups. In this view, context not only determines the exposure to the risk and protective factors, it also changes the vulnerability and resilience to them. Thus we need to better understand how ethnicity, gender, place, and their intersections modify separate, additive, and multiplicative effects of risk and protective factors on depression.
\end{abstract}

Keywords: Depression, Ethnic Groups, Gender, Women, War

Article History: Received: 7 Mar 2015 Revised: 25 May 2015 Accepted: 30 May 2015

Cite this article as: Assari S, Micol-Foster V, Dejman M, Ayoubian A, Lankarani MM. Contextual Effects of ethnicity, gender, and place on depression; case study of war related stress for Kurdish women. Int J Travel Med Glob Health. 2015; 3(2):83-91.

\section{Gender and Depression}

Epidemiologic data from diverse regions and cultures has consistently indicated that the lifetime prevalence of major depression is higher in women compared to men [1-4]. Cross-country studies have also confirmed that women have higher prevalence of depression than men in all countries [3, 5].

Social factors have shown to be responsible at least for some of the gender differences in rate of depression, as the gender gap in depression is larger in countries with higher gender inequalities [6]. Cross-country comparisons have also shown that socioeconomic and family-related factors moderate magnitude of the gender disparities in depression. Thus, not only do social factors predict depression, they also - at least partially - explain why women have a higher rate of depression than men [3].

\section{Social Causes of Depression}

The social environment that each population lives in has unique characteristics, each with a unique impact on the causation, chronicity, and recurrence of depression [7]. Social environment influences the risk of depression as it determines frequency and severity of exposure to events and processes that can potentially interfere with individuals' effort to fulfill life goals. Thus, both the number (quantity) and the character (quality) of the undesired and disruptive events and processes contribute to the likelihood of developing depression [8]. Unfortunately, less is known about the effect of higher level factor (i.e. social environment attributes) on depression compared to the effect of individual factors on depression. Over the past few years, there has been an increasing interest in contribution of higher order factors on depression. Most of this research has shown that poor physical and social environment increases risk of depression [9-10].

\section{Gender and Psychosocial Causes of Depression}

Based on psychosocial theories of depression, predominance of lifetime depression in women is at least in part due to the higher exposure and/or vulnerability of women to a wide range of social stressors, both during childhood and adulthood [11-12].

In addition to the biological mechanisms [13-14], gender differences in unemployment, stressful life events, child-care 
responsibilities, domestic violence, and social isolation may partially explain the higher rate of depression among women compared with men [15]. While mechanisms of higher prevalence of depression among women are not fully understood, main hypotheses highlight the role of different responses to stressful life events, genetic predisposition, and hormonal differences [16].

While men and women are both sensitive to the effects of stressful life events on depression, gender may determine psychological response to each type of stressor. While men are more likely to have depressive episodes following work difficulties, divorce, and separation, women are more sensitive to stressful life events such as conflict, serious illness, or death happening in their proximal social network [17-18]. These findings suggest that psychosocial causes of depression may be at least partially gender-specific [19].

Some evidence suggests that stressors and factors that explain higher vulnerability of women to major depression tend to be of interpersonal nature $[11,20]$. In this view, social stressors that cause depression among women tend to more frequently happen in an interpersonal context. Most of the stressful events that cause depression among women are related to their close social network, such as romantic and marital relationships, childrearing, and parenting [20]. Research has also suggested that parental warmth, divorce, social support, and marital satisfaction may have a larger impact on depression of women, compared to men [21].

In a study by Kelly et al., in 2008, although cortisol reactivity and the magnitude of autonomic responding failed to reliably discriminate between women and men, women reported more fear, irritability, confusion and less happiness immediately following the stress test compared to men [22]. The findings reported by Kelly et al., and others suggest that some of the gender differences in depression may be explained by the gender differences in stress sensitivity [22].

Higher rumination of stressors and negative thoughts among women may explain higher levels of depression among women [23-29]. A Meta analysis has shown that women score higher than men in rumination, brooding, and reflection, which all contribute to depression following exposure to stress [30]. In a study, higher rumination, chronic strain, and low mastery were more common in women than in men and mediated the gender difference in depressive symptoms [31].

\section{Place and Depression}

Cross-national studies have shown that (lifetime and past year) prevalence and course of depression vary substantially across countries and regions [32-33]. For instance, the lifetime rate for major depression was 15 times higher in Beirut (19\%) than in Taiwan (1.5\%), and the annual rate of depression was 15 times higher in New Zealand (0.8) than Taiwan (5.8) [32]. Another cross-national comparison included 10 population-based studies that had used the WHO
Composite International Diagnostic Interview (CIDI and showed that the lifetime prevalence estimates of MDD ranged from $1.0 \%$ (Czech Republic) to $16.9 \%$ (US), and the 12-month prevalence estimates ranged from $0.3 \%$ (Czech Republic) to $10 \%$ (US) [34]. Moussavi et al. also showed cross-country differences in rates of depression in the WHO World Health Survey across 60 countries [35]. Place also influences prevalence of depression within countries [70]. Kessler et al., has also shown that some psychosocial correlates of depression vary across countries [33].

\section{Place, Social Environment and Depression}

There is a growing literature suggesting that the effect of place on risk of depression among populations and individuals may be through social and physical attributes of the environment [9]. In a study in the United States, compared to the respondents living in neighborhoods characterized by better features of the built environment, persons living in neighborhoods with poorer features of the built environment were $29 \%-58 \%$ and $36 \%-64 \%$ more likely to report depression during the past six months and lifetime, respectively [9].

A systematic review evaluated 45 English-language crosssectional and longitudinal studies that had tested the effect of neighbourhood-level factors on either depression or depressive symptoms. In $82 \%$ of studies $(n=37)$ associations were found between neighborhood characteristics and depression or depressive symptoms. 70\% of longitudinal studies reported that neighborhood characteristics predict incident depression over time. In these studies, social environment was a stronger predictor of depressive symptoms and depression than built environment and structural features such as socioeconomic and racial composition of the neighborhood [36].

Neighborhood poverty level moderates the effects of ethnicity on mental health service access and use, as disparities in using emergency and inpatient services are more evident in low-poverty than in high-poverty areas. Neighborhood poverty is a key to understanding racial/ethnic disparities in the use of mental health services [37].

Although social environment shapes individual life experiences that contribute to the causation, chronicity, and recurrence of depression [7], the effect of social environment may be stronger for women compared to men $[11,20]$. Some evidence suggests that men and women may differ in how their physical and social environment increases their risk of depression [38]. For instance, one study showed that poverty is linked to depression, particularly in women, and availability of support from friends significantly moderated the poverty- depression link among older women [39]. This suggests that social support may be a protective factor that may be leveraged to increase resilience to depression for women in particular. 


\section{Ethnicity and Depression}

Ethnicity influences risk, presentation, and chronicity of depression [40-43]. Ethnicity also modifies demographic correlates of depression [44]. Ethnicity also changes health care use associated with mental health problems [45-46]. The conceptualization of illness, as well as the manifestation of its symptoms, responses to the illness, and methods of treatment is largely determined by the society's culture in different ethnic groups [17-18].

Ethnicity influences the source of distress, attribution of stress, the interpretation of symptoms and the psychosocial response to distress [17-18]. A study that compared Koreans and Europeans for predictors of depression showed ethnicity and culture moderate the risk factors. For Korean youth, perceived parental traditionalism, and perceived parental modernism were predictors of depression while for Caucasian youth, predictors were academic stress and respondents own modern values [47].

Culture also modifies causal beliefs about depression [48]. Thus each cultural and ethnic group of women may have its own social causes of depression [17-18, 49]. For instance, there is some evidence suggesting that Kurd women are different in social origin of depression. That is, social stressors outside interpersonal environment may have a large contribution to the causation, chronicity, and recurrence of depression among Kurd women [50].

Social stressors are believed to be a function of context and are specific to environmental situation. So, social stressors (as causes of depression) have correlation to existing situation and events that each ethnic group is experiencing [5154].

\section{Gender, Ethnicity, and Depression}

In a series of studies, Assari has shown that race, ethnicity, gender, and their intersections change psychosocial correlates of depression and depressive symptoms [37-38, 55-62]. In a longitudinal study of Blacks who were transitioning to young adulthood, gender moderated if an increase in fear of neighborhood violence predicted subsequent increase in depressive symptoms over time [38]. In another study among Blacks in the U.S., ethnicity and gender interacted in shaping the effect of need for mental health care on inpatient mental health care utilization [55].

\section{Gender, ethnicity, place, and resilient factors}

It is also important to note that gender, ethnicity, and place influence access and use of assets and resources that protect individuals against depression. Research has consistently shown that self-esteem [63], sense of control over life [64], religiosity [65], and social support [66-68] have strong protective effects against depression. However, these resources and assets are differently available for different social groups. In addition to access and use, vulnerability to these personal factors also differs across groups.
Self-esteem determines risk of development of subsequent depression over time [69]. Individuals with high self-esteem also have higher chance of recovery from depression and may better respond to cognitive behavioral therapies for depression [70]. Religiosity decreases risk of depression [7172], helps individuals recover from depression [73] and lowers negative consequences of depression such as cognitive decline [74] and suicide [75]. High social support also reduces severity [76] and chronicity [77] of depression and increases chance of early recovery from depression [78]. The effect of these protective factors, however, overlap, and social support may mediate some of the effect of religion [59, 79]. A well-known overlap also exists between social support and sense of control, as social support enhances perceived control over life [80].

There is a gender gap in the sense of personal control over life [81]. A number of studies have shown that women feel less in control of their own lives than men [82-84]. Gender differences in the quantity and quality of exchange of social support with friends, neighbors, and co-workers are well known [85]. Women tend to use more social support than men [86]. Finally, women consistently report more religious and spiritual beliefs and public and private religious practices [87-88].

Cross-country comparisons have shown that structure and function of social networks are under influence of race, and ethnicity, and place [89]. Observed differences in the structural bases and functional elements of social support across communities have been attributed to their different cultural and historical characteristics [89]. Higher use of social support in ethnic minority groups is well documented [90]. For instance, in the United States, the church is a well-documented source of support for African Americans [91-92] and African American children develop self-worth, comfort and hope from religion [93].

Among older adults, researchers have shown that religious service attendance may help decrease cognitive decline in older women but not men with depression [74]. Social support may also differ in their effects on mental health across racial and ethnic populations. For whites, negative interaction was an overall stronger predictor of distress and contributed to the impact of financial strain and traumatic events on psychological distress. Among African Americans, social support was a stronger predictor of distress [94]. In a study, church-based social support mediated the effect of church attendance on overall mental health and life satisfaction among African Americans but not Caribbean Blacks, or Whites [59]. In a study, for White elderly, high social support and large social network reduced the effect of stress on depressive symptoms, while for black elderly, having more network members and receiving support from them was associated with a stronger link between stress and depressive symptomatology [95]. This may be because need for social support among Blacks may be a proxy of greater financial 
difficulty [95]. In another study, high instrumental support was associated with higher disability risk, with a greater adverse effect for Whites than Blacks [96]. Religious and spiritual beliefs are particularly a source of resiliency among racial and ethnic minority groups [97-99] to deal with environmental stressors $[93,100]$.

Thus although self-esteem, sense of control, social support, religiosity, and other resilient factors are important factors that protect against depression, their effects depend on contextual factors including but not limited to ethnicity, gender, and place. A deeper understanding about populationspecific relevance and implication of resilient factors for depression of various groups is required. Such a better understanding may have clinical and public health implications for prevention, detection, and treatment of depression, particularly among minority groups.

\section{Case Study}

\section{War and Depression}

Although non-mood psychiatric disorders such as post-traumatic stress disorder, anxiety, and increased alcohol and smoking develop following war, depression also requires attention among civilians who have experienced war [101105]. The WHO has emphasized the mental health impact of war and other armed conflicts throughout the world by mentioning: "10\% of the people who experience traumatic events will have serious mental health problems and another $10 \%$ will develop behavior that will hinder their ability to function effectively" [106]. Most of the research on the psychological effects of war, however, has traditionally focused on the effect of war on PTSD among veterans [107], and less is known about the role of war in increasing the risk of depression among civilians, particularly women [108].

It is noteworthy that WHO lists depression first and before other conditions such as anxiety, psychosomatic problems, insomnia, and pain, as major mental health consequences of war [106]. In a study published in JAMA in 2004 on mental health effects of war on general population in Afghanistan, $43.7 \%$ of respondents had experienced between 8 and 10 traumatic events and $14.1 \%$ of responded had experienced 11 or more events during the past 10 years. High depressive symptoms were reported by $38.5 \%$; which was more common than PTSD (20.4\%). High symptoms of depression were more prevalent in women than in men (odds ratio $=7.3$ ) [109]. Karam and colleagues conducted studies of lifetime prevalence, age of onset, and treatment delay for mental disorders on a nationally representative population in Lebanon. The studies have shown that nearly $70 \%$ of the population was exposed to one or more war events (such as being a civilian in a war zone) and about $38 \%$ of the population had been war refugees. Almost half of the Lebanese population was exposed to one or two war events; and $22 \%$ were exposed to three or more war events. These studies have shown that war exposure (individual and cumulative risk) is a very strong risk factor for the development of mental disorders such as depression $[108,110]$.

Most civilians who are exposed to war survive and many leave their cities and villages, becoming refugees. Refugees of armed conflicts leave most of their wealth and assets behind and many live in extremely difficult humanitarian conditions. In addition, in most cases, refugees will become religious and ethnic minorities, regardless of which country they go to. All these harsh conditions place them at great risk of depression [111]. These difficult situations are being compounded by the lack of electricity, shortage of water, medical supplies and expertise. Civilians also suffer from fears of sporadic aerial attacks [112]. According to the UN, following civil war in Syria, the scarcity of food forced religious clerics to issue edicts allowing people to eat cats and dogs in order to survive [112].

\section{Kurds in Middle East}

Kurdish people are the largest stateless nation in the world. As a result, Kurds are ethnic minorities in all countries that they live in [113]. Kurds mostly live in the Middle East, inhabiting a contiguous area spanning adjacent parts of southeastern Turkey (Northern Kurdistan), western Iran (Eastern Kurdistan), northern Iraq (Southern Kurdistan), and northern Syria (Western Kurdistan). About 28 million Kurds live in the Middle East, 14.5 million in Turkey, 6 million in Iran, 6 million in Iraq, and about 2 million in Syria [114].

\section{War and other Stressors among Kurdish People}

In Iran, Kurds are concentrated in the western, mountainous areas of the country, in the provinces such as Kurdistan which were heavily involved in the Iraq-Iran war [115]. During the Iran-Iraq war, Kurdistan was heavily bombarded by Iraq. In addition to the Iraq-Iran war, Iranian Kurdish people have been engaged in civil war for years [116]. During years of war, trauma and loss were a daily life experience for Kurdish people. These stressors are above other social problems and long-term stressors (i.e. low income and unemployment) that they encounter [117].

In Iraq, Kurds have lived through decades of political oppression, particularly under Saddam Hussein whose government conducted a campaign of persecution and genocide ('the Anafal') against Iraqi Kurdistan. The campaign included bombing, chemical warfare, and forced dislocations [112,118]. Between 1986-9, 50 to 100 thousand Kurds were killed and 4,000 villages were destroyed [119-121]. Iraq bombarded Iraq's Kurdistan with chemical weapons towards the end of the Iran-Iraq War, which was considered genocide [122]. The chemical attack on Halabja city killed 5,000 civilians [112,119,121]. Arbitrary imprisonment, torture, and mass killings were also commonly applied against Kurds in Iraq [123-124].

\section{Depression among Kurds}

Very few studies have been conducted on depression among 
Kurds. Cummings et al., conducted a study on 70 older Kurdish refugees who had immigrated from war-torn areas in the Middle East and were living in one city in the United States. The majority of participants had very low incomes; had no education; were illiterate in their own language; and had little to no ability to speak, read, or write English. Elevated levels of depression (scoring above the clinical cutoff) were found in $67 \%$, with $26 \%$ scoring in the severe depression range. In addition to demographic (age), stressor (migratory grief, death of spouse, number of medical conditions, functional disability, and income), and coping (English proficiency and social support), health conditions, and social support, migratory grief was a significant predictor of depression [125].

\section{Suicide among Kurdish Women}

Surging suicide rates have been reported among women in the Kurd regions of Turkey, Iraq and Iran [126-127]. High levels of suicide deaths are particularly important because women have consistently shown to less frequently commit suicide, despite higher levels of ideation [128].

Although women tend to use less lethal means for suicidal attempt [129-130], fatal self-burnings are very common among Kurd women in Iran and Iraq [126,131]. Some of the known stressors that influence risk of depression and suicide among Kurds include discrimination, honor killings, and migration [50].

High suicide rate among Iranian Kurd women who live in Ilam has been frequently reported [127, 132-134]. In another study in Sannadaj, another place that Kurds live, $6.3 \%$ of the investigated group reported a suicide attempt lifetime. 19.5 $\%$ of subjects who reported a suicide attempt during the last year reported also that they had experienced suicide related thoughts in the last year [49].

\section{War as a Cause of Depression among Kurd Women}

A high number of Kurd women have witnessed sexual torture and rape by security forces in wars [50]. A report on mental health effect of war and related stressors among Kurd women suggested there are very complex patterns and forms of patriarchal violence that Kurd women are confronted with that do not match the "traditional" social structures. Such violence can be life threatening for Kurd women and for women in other societies [50].

It is extremely important to understand the very stressful conditions of being exposed to severe forms of violence that threaten the lives of Kurd women [50]. We argue that it is not only PTSD or anxiety disorders, but also depression, as an important, prevalent, chronic, and disabling, and costly consequence of war for Kurd women.

Kurd ethnic groups have reported different social causes for depression [135]. It has been suggested that traumatic life events and losses are two common phenomena for the Kurds [115]. In a study by Dejman et al., war (Iraq-Iran was from 1980 to 1988) and its consequences was mentioned as a social cause of depression by the majority of the Kurd participants. Fear and anxiety during that time, and the war's consequences, such as the city's underdevelopment and lack of facilities, were seen as major external factors contributing to depression for women in that region [135].

\section{Context and Depression Therapy for Kurds}

A successful example for detection and treatment of depression and other mental health problems among Kurds is the Trauma Rehabilitation and Training Center (TRTC) in Sulaymaniyah, Iraq. The center was founded in 2006 collaboratively by local doctors, John Hopkins University, and the Heartland Alliance (a Chicago-based NGO). Since 2006, the center has treated over six hundred patients, mostly for depression or PTSD related to war. Patients' histories have shown high levels of war related trauma [112]. The center has provided comprehensive services for trauma survivors and training for mental health workers, which is ideal for such resource limited contexts. The TRTC assists approximately 250 torture survivors annually, most of whom are Kurds. In 2011, the TRTC became an independent organization under the auspices of a newly-formed local NGO, Wchan for Victims of Human Rights Violations [112].

The following case is one example of the many success stories of the center: A 47-year-old Iraqi Kurd man with severe depression and PTSD is treated by the TRTC. After full recovery, he states: "I compare myself to a wild injured animal that couldn't see any assistance and had no hope of getting help, but all of a sudden a helicopter came and provided medical aid, food, and cured my wounds. The helicopter I am describing is the Trauma Rehabilitation and Training Center." [136].

There are also innovative interventions that consider the context and specific cause of depression in the treatment of depression. Some of these efforts have shown very promising results for treatment of war related depression in such environments. In 2014, Bolton et al., published a study to compare two psychotherapeutic interventions, Behavioral Activation Treatment for Depression (BATD) and Cognitive Processing Therapy (CPT), in reducing depression symptoms using a locally adapted and validated scales. The study demonstrated that effective context-specific interventions can be designed and implemented that matches the needs of context, in this case, using mental health workers with limited prior experience [137].

\section{Implications}

Extreme severe environmental conditions and social stressors related to war provides an explanation for high levels of depression and suicide among Kurd women [126-127, 135]. Although psychological difficulties can also result in resilience [138-139], high levels of prolonged exposure to environmental stressors increases risk of depression and distress [140-141]. Although war has been historically a cause of depression among Kudish people, war - as a unique cause of 
depression among civilians and specially Kurd women - has not received scholarly attention [50].

Particularly in the geographic regions with high density of Kurds, national and international public mental health response to the ongoing large-scale catastrophic wars is required [101-105].

Unfortunately extremely high levels of fatal suicide among Kurd women have received trivial attention by researchers, and also women's rights organizations and the media [50]. There is also a need for future research on mental health effects of war and threats by unique environmental stressors in the region.

The mental health consequences of the emerging threats that increase risk of war in the Middle East should not be undermined. One recent example is the radical Islamist groups such as Islamic State of Iraq and the Levant (ISIL), also called Islamic State of Iraq and Syria or the Islamic State of Iraq and ash-Sham (ISIS) or Islamic State. The mental health effect of evolvements of such crises may be very high among Kurds in Iraq and Syria [105]. This is also important for other religious and ethnic minorities in the regions which can be a target for such terrorist, extremist, and "jihadist" groups.

The additive and synergistic effects of wars, national and ethnic discrimination, disadvantaged living conditions, blocked opportunities, migration and forced displacement, and massacres and oppression all collectively contribute to the risk of depression in the geographic regions that Kurd people live. These factors should be considered as an area of research, intervention, and policy for mental health practice and policy regarding Kurd women's mental health [50].

Similar to other minority groups [142] who report high levels of discrimination and social stress [143], and if depressed, they less frequently have access to mental health care services, experience higher levels of stigma and mistrust [144], Kurdish women with depression may require specific interventions for promotion of mental health care use. Thus, they require specific programs for screening, diagnosis, and treatment of depression.

Interventions to the mental health of Kurdish women may not be simple and may require a thorough understanding of and consideration of their life values, discrimination, religion, national and ethnic identity, and exposure to war and other stressors. Studies in the intersection of social epidemiology, gender/sex studies, sex differences, and cultural psychology/psychiatry are required, to better understand ethnic and gender specific causes of depression among Kurdish women [113, 135, 145-146].

War has been and still is a unique and important social cause of depression among Kurds and Kurd women in the Middle East. This may partially explain why depression and suicide are common among Kurd women. This is important because in many countries Kurds are an ethnic minority group who experience political suppression, which increases the risk of adversity and hinders access to social power and mental health care if needed $[144,146]$.
Although literature has suggested that inter-personal stressors may have a more prominent role for depression among women, in the case of Kurd women, war may be a unique social stressor. This case study emphasizes the role of contextual factors such as ethnicity, gender, place, and their intersections in determining what types of stressors cause depression. This again highlights the role of context and social conditions that populations live in.

Risk of depression cannot be understood among Kurdish people without understanding their culture, and also national, economic and political oppressions that they experience in Turkey, Iran, Iraq, and Syria [50].

\section{Conclusion}

This case study highlighted the role of war as a population specific stressor that has caused depression among Kurd women. We hope this can serve as an example on how social causes of depression are under the influence of the intersection of ethnicity, gender, and place.

There are enough accumulated scientific evidence confirming that in addition to their direct effects, ethnicity, gender, and place have contextual (indirect) effects on depression in populations. In this view, context not only determines the exposure to the risk and protective factors, it also changes the vulnerability and resilience to them. This emphasized the need for understanding group-differences in the separate, additive, and multiplicative effects of risk and protective factors on depression. We argue that the intersection of ethnicity, gender, and place captures some of the heterogeneity of depression across populations, and can be used for tailored programs for screening, detection, prevention, and treatment of depression.

\section{References}

1. Nolen-Hoeksema, S. Gender differences in depression. Current directions in psychological science 2001:10(5):173-6.

2. Weissman MM, Bland R, Joyce PR, Newman S, Wells JE, Wittchen HU. Sex differences in rates of depression: cross-national perspectives. J Affect Disord. 1993;29(2-3):77-84.

3. Van de Velde S, Bracke P, LevecqueK. Gender differences in depression in 23 European countries. Cross-national variation in the gender gap in depression. SocSci Med. 2010;71(2):305-13.

4. Hopcroft RL. Bradley DB. The Sex Difference in Depression across 29 Countries. Social Forces. 2007;85(4):1483-507.

5. Seedat S, Scott KM, Angermeyer MC, Berglund P, Bromet EJ, Brugha TS, et al. Cross-national associations between gender and mental disorders in the World Health Organization World Mental Health Surveys. Arch Gen Psychiatry. 2009;66(7):785-95.

6. Van de Velde S, Huijts T, Bracke P, Bambra C. Macro-level gender equality and depression in men and women in Europe. Sociol Health Illn. 2013;35(5):682-98.

7. Miles R, Coutts C, Mohamadi A. Neighborhood urban form, social environment, and depression. J Urban Health. 2012;89(1):1-18.

8. Fullilove MT. Social and economic causes of depression. J Gend Specif Med. 2002;5(2):38-41.

9. Galea S, Ahern J, Rudenstine S, Wallace Z, Vlahov D. Urban built environment and depression: a multilevel analysis. J Epidemiol Community Health. 2005;59(10):822-7.

10. Tomita A, Burns JK. A multilevel analysis of association between neighborhood social capital and depression: evidence from the first South African National Income Dynamics Study. J Affect Disord. 2013;144(1-2):101-5

11. Desai HD, Jann MW. Major depression in women: a review of the literature. J Am Pharm Assoc (Wash). 2000;40(4):525-37. 
12. Oldehinkel AJ, Bouma EM. Sensitivity to the depressogenic effect of stress and HPA-axis reactivity inadolescence: a review of gender differences. Neurosci Biobehav Rev. 2011;35(8):1757-70.

13. Halbreich U, Vital-Herne J, Goldstein S, Zander K. Sex differences in biological factors putatively related to depression. J Affect Disord. 1984;7(3-4):223-33.

14. Halbreich U, Lumley LA. The multiple interactional biological processes that might lead to depression and gender differences in its appearance. J Affect Disord. 1993;29(2-3):159-73.

15. Hussain F, Cochrane R. Depression in South Asian Women Living in the UK: A Review of the Literature with Implications for Service Provision. Transcultural Psychiatry, 2004;41(2):253-70.

16. National Institute of Mental Health. Women and depression: discovering hope. Bethesda, MD: US Department of Health and Human Services, National Institutes of Health, National Institute of Menta Health; 2009. Available at http://www.nimh.nih.gov/health/publications/women-and-depression-discovering-hope/index.shtmlExternal Web Site Icon. Accessed September 27, 2010.

17. Kirmayer L, Groleau D. Affective disorders in cultural context. Psychiatric Clinics of North America. 2001;24(3):465-78

18. Kleinman A. Culture and Depression. New England J Med 2004;351(10):951-52

19. Hasler G. Pathophysiology of depression: do we have any solid evidence of interest to clinicians? World Psychiatry. 2010;9(3):155-61.

20. Hammen C. Interpersonal stress and depression in women. J Affect Disord. 2003;74(1):49-57.

21. Kendler KS, Gardner CO. Sex differences in the pathways to major depression: a study of opposite-sex twin pairs. Am J Psychiatry. 2014;171(4):426-35

22. Kelly MM, Tyrka AR, Anderson GM, Price LH, Carpenter LL. Sex differences in emotional and physiological responses to the Trier Social Stress Test. J Behav Ther Exp Psychiatry. 2008;39(1):87-98.

23. Michl LC, McLaughlin KA, Shepherd K, Nolen-Hoeksema S. Rumination as a mechanism linking stressful life events to symptoms of depression and anxiety: longitudinal evidence in early adolescents and adults. J Abnorm Psychol. 2013;122(2):339-52.

24 Peden AR, Hall LA, Rayens MK, Beebe L. Negative thinking mediates the effect of self-esteem on depressive symptoms in college women. Nurs Res. 2000;49(4):201-7.

25. Evans J, Heron J, Lewis G, Araya R, Wolke D; ALSPAC study team. Negative self-schemas and the onset of depression in women: longitudinal study. Br J Psychiatry. 2005;186:302-7.

26. Butler LD, Nolen-Hoeksema S. Gender differences in responses to depressed mood in a college sample. Sex Roles. 1994;30:331-46.

27. Nolen-Hoeksema S. Harrell ZAT. Rumination, depression and alcohol use: Tests of gender differences. Journal of Cognitive Psychotherapy: An International Journal. 2002;16:391-404.

28. Nolen-Hoeksema S, Jackson, B. Mediators of the gender difference in rumination. Psychology of Women Quarterly 2001;25:37-47.

29. Nolen-Hoeksema S, Larson J, Grayson C. Explaining the gender difference in depressive symptoms. Journal of Personality and Social Psychology 1999, 77, 1061-1072.

30. Johnson DP, Whisman MA. Gender differences in rumination: A meta-analysis. Pers Individ Dif. 2013;55(4):367-374.

31. Nolen-Hoeksema S, Larson J, Grayson C. Explaining the gender difference in depressive symptoms. $J$ Pers Soc Psychol. 1999;77(5):1061-72.

32. Weissman MM, Bland RC, Canino GJ, Faravelli C, Greenwald S, Hwu HG, Joyce PR, Karam EG, Lee CK, Lellouch J, Lépine JP, Newman SC, Rubio-Stipec M, Wells JE, Wickramaratne PJ, Wittchen H, Yeh EK. Cross-national epidemiology of major depression and bipolar disorder. JAMA. 1996;276(4):293-9.

33. Kessler RC, Bromet EJ. The epidemiology of depression across cultures. Annu Rev Public Health. 2013;34:119-38.

34. Andrade L, Caraveo-Anduaga JJ, Berglund P, Bijl RV, Dragomericka $\mathrm{E}$, et al. The epidemiology of major depressive episodes: results from the International Consortium of Psychiatric Epidemiology (ICPE) Surveys. Int J Methods Psychiatr Res. 2003;12:3-21.

35. Moussavi S, Chatterji S, Verdes E, Tandon A, Patel V, Ustun B. Depression, chronic diseases, and decrements in health: results from the World Health Surveys. Lancet. 2007;370:851-858.

36. Mair C, Diez Roux AV, Galea S. Are neighbourhood characteristics associated with depressive symptoms? A review of evidence. J Epidemiol Community Health. 2008;62(11):940-6.

37. Chow JC, Jaffee K, Snowden L. Racial/ethnic disparities in the use of mental health services in poverty areas. Am J Public Health 2003;93(5):792-7.

38. Assari S, Smith J, Caldwell CH. Gender Differences in Longitudina Links between Neighborhood Fear, Parental Support, and Depression among African American Emerging Adults. Societies 2015:5(1):151 70 .
39. Kim J, Richardson V, Park B, Park M. A multilevel perspective on gender differences in the relationship between poverty status and depression among older adults in the United States. J Women Aging. 2013;25(3):207-26.

40. Dunlop DD, Song J, Lyons JS, Manheim LM, Chang RW. Racial/ethnic differences in rates of depression among preretirement adults. Am J Public Health. 2003;93(11):1945-52.

41. Lee SY, Xue QL, Spira AP, Lee HB. Racial and ethnic differences in depressive subtypes and access to mental health care in the United States. J Affect Disord. 2014;155:130-7.

42. Iwata N, Buka S. Race/ethnicity and depressive symptoms: a crosscultural/ethnic comparison among university students in East Asia, North and South America. Soc Sci Med. 2002;55(12):2243-52.

43. Roberts RE. Manifestation of depressive symptoms among adolescents. A comparison of Mexican Americans with the majority and other minority populations. J Nerv Ment Dis. 1992;180(10):627-33.

44. Aranda MP, Chae DH, Lincoln KD, Taylor RJ, Woodward AT, Chatters LM. Demographic correlates of DSM-IV major depressive disorder among older African Americans, Black Caribbeans, and nonHispanic Whites: results from the National Survey of American Life. Int J Geriatr Psychiatry. 2012;27(9):940-7.

45. Neighbors HW, Caldwell C, Williams DR, Nesse R, Taylor RJ, Bullard KM, Torres M, Jackson JS. Race, ethnicity, and the use of services for mental disorders: results from the National Survey of American Life. Arch Gen Psychiatry. 2007;64(4):485-94.

46. Williams DR, González HM, Neighbors H, Nesse R, Abelson JM, Sweetman J, Jackson JS. Prevalence and distribution of major depressive disorder in African Americans, Caribbean blacks, and non-Hispanic whites: results from the National Survey of American Life. Arch Gen Psychiatry. 2007;64(3):305-15.

47. Aldwin C, Greenberger E. Cultural differences in the predictors of depression. Am J Community Psychol. 1987;15(6):789-813.

48. Caplan S, Escobar J, Paris M, Alvidrez J, Dixon JK, Desai MM, Scahill LD, Whittemore R. Cultural influences on causal beliefs about depression among Latino immigrants. J Transcult Nurs. 2013;24(1):68-77.

49. Mofidi N, Studies on mental health in Kurdistan - Iran. UMEÅ University. Umeå, Sweden, 2010.

50. International Free Women's Foundation, Depression in migrants and ethnic minorities Psychological Consequences of Trauma Experiences on the Development of Migrated Kurdish Women in the European Union. Final Results and Background of a Survey in Five European Countries and Turkey. Paris. Rotterdam Utrecht University, Department of Clinical and Health Psychology Kurdistan Information Office, 2007.

51. Shalowitz MU, Mijanovich T, Berry CA, Clark-Kauffman E, Quinn KA, Perez EL. Context matters: a community-based study of maternal mental health, life stressors, social support, and children's asthma. Pediatrics. 2006;117(5):e940-8

52. Copeland-Linder, Nikeea, et al. Contextual stress and health risk behaviors among African American adolescents.Journal of youth and adolescence. 2011;40(2):158-73.

53. Riley MR, Scaramella LV, McGoron. Disentangling the associations between contextual stress, sensitive parenting, and children's social development. Family Relations. 2014;63(2):287-99.

54. Cunningham, Michael, et al. Influence of perceived contextual stress on self-esteem and academic outcomes in African American adolescents. Journal of Black Psychology. 2002;28(3):215-33.

55. Assari S. Ethnicity, Gender, Need for Mental Health Care and Inpatient Mental Health Care Utilization among American Blacks. Annals of Epidemiology. 2011;23(9):589.

56. Assari S. Additive Effects of Anxiety and Depression on Body Mass Index among Blacks: Role of Ethnicity and Gender. Int Cardiovasc Res J. 2014;8(2):44-51.

57. Assari S. Separate and Combined Effects of Anxiety, Depression and Problem Drinking on Subjective Health among Black, Hispanic and Non-Hispanic White Men. Int J Prev Med. 2014;5(3):269-79.

58. Assari S, Lankarani MM, Lankarani RM. Ethnicity Modifies the Additive Effects of Anxiety and Drug Use Disorders on Suicidal Ideation among Black Adults in the United States. Int J Prev Med. 2013;4(11):1251-7.

59. Assari S. Race and Ethnicity, Religion Involvement, Church-based Social Support and Subjective Health in United States: A Case of Moderated Mediation. Int J Prev Med. 2013;4(2):208-17.

60. Assari S. Association between obesity and depression among American Blacks: Role of ethnicity and gender. Journal of Racial and Ethnic Health Disparities 2014; 1(1): 36-44

61. Assari S, Caldwell CH. Gender and ethnic differences in the association between obesity and depression among black adolescents. Journal of Racial and Ethnic Health Disparities. 2015;2(1):1-13. 
62. Assari S. The link between mental health and obesity: role of individual and contextual factors. Int J Prev Med. 2014;5(3):247-9

63. Sowislo JF, Orth U. Does low self-esteem predict depression and anxiety? A meta-analysis of longitudinal studies. Psychol Bull. 2013;139(1):213-40.

64. Evans RG. The relationships of two measures of perceived control to depression. J Pers Assess. 1981;45(1):66-70.

65. Bonelli RM, Koenig HG. Mental disorders, religion and spirituality 1990 to 2010: a systematic evidence-based review. J Relig Health 2013;52(2):657-73

66. Grav S, Hellzèn O, Romild U, Stordal E. Association between social support and depression in the general population: the HUNT study, a cross-sectional survey. J Clin Nurs. 2012;21(1-2):111-20.

67. Paykel ES. Life events, social support and depression.Acta Psychiatr Scand Suppl. 1994;377:50-8

68. Vilhjalmsson R. Life stress, social support and clinical depression: a reanalysis of the literature. Soc Sci Med. 1993;37(3):331-42.

69. Orth U, Robins RW2, Widaman KF2, Conger RD3. Is low self-esteem a risk factor for depression? Findings from a longitudinal study of Mexican-origin youth. Dev Psychol. 2014;50(2):622-33.

70. Parker TJ, Page AC, Hooke GR. The influence of individual, group, and relative self-esteem on outcome for patients undergoing group cognitive-behavioural therapy treatment. $\mathrm{Br} \mathrm{J}$ Clin Psychol. 2013;52(4):450-63

71. Bonelli R, Dew RE, Koenig HG, Rosmarin DH, Vasegh S. Religious and spiritual factors in depression: review and integration of the research. Depress Res Treat. 2012;9(6):28-60.

72. McCullough ME, Larson DB. Religion and depression: a review of the literature. Twin Res. 1999;2(2):126-36.

73. Braam AW, Beekman AT, Deeg DJ, Smit JH, van Tilburg W. Relig iosity as a protective or prognostic factor of depression in later life; results from a community survey in The Netherlands. Acta Psychiatr Scand. 1997;96(3):199-205

74. Corsentino EA, Collins N, Sachs-Ericsson N, Blazer DG. Religious attendance reduces cognitive decline among older women with high levels of depressive symptoms. J Gerontol A Biol Sci Med Sci. 2009;64(12):1283-9.

75. Assari S, Lankarani MM, Moazen B. Religious Beliefs May Reduce the Negative Effect of Psychiatric Disorders on Age of Onset of Suicidal Ideation among Blacks in the United States. Int J Prev Med. 2012:3(5):358-64.

76. Olagunju AT, Olutoki MO, Ogunnubi OP, Adeyemi JD. Late-life depression: Burden, severity and relationship with social support dimensions in a West African community. Arch Gerontol Geriatr. 2015. pii: S0167-4943(15)00071-0.

77. Brugha T, Bebbington PE, MacCarthy B, Potter J, Sturt E, Wykes T Social networks, social support and the type of depressive illness. Acta Psychiatr Scand. 1987;76(6):664-73.

78. Brugha TS, Bebbington PE, MacCarthy B, Sturt E, Wykes T, Potter J. Gender, social support and recovery from depressive disorders: a prospective clinical study.Psychol Med. 1990;20(1):147-56.

79. Rasic DT, Belik SL, Elias B, Katz LY, Enns M, Sareen J; Swampy Cree Suicide Prevention Team. Spirituality, religion and suicidal behavior in a nationally representative sample. J Affect Disord 2009; 114(1-3):32-40

80. Nemeroff R, Midlarsky E, Meyer JF. Relationships among socia support, perceived control, and psychological distress in late life. Int J Aging Hum Dev. 2010;71(1):69-82.

81. Ross CE, Mirowsky J. Age and the gender gap in the sense of personal control. Social Psychology Quarterly. 2002;125-145.

82. Mirowsky J, Ross CE. Paranoia and the Structure of Powerlessness. American Sociological Review. 1983;4(8):228-39.

83. Ross CE, Mirowsky J. Mexican Culture and Its Emotional Contradictions. Journal of Health and Social Behavior. 1984;2(5):2-13.

84. Ross CE, Wright MP, Women's Work, Men's Work and the Sense of Control. Work Occupations. 1998;25:33-55.

85. Liebler CA, Sandefur GD. Gender differences in the exchange of social support with friends, neighbors, and co-workers at midlife. Social Science Research. 2002;31(3):364-91.

86. Bellman S, Forster N, Still L, Cooper CL. Gender differences in the use of social support as a moderator of occupational stress. Stress and Health. 2003;19(1):45-58

87. Shahabi L, Powell LH, Musick MA, Pargament KI, Thoresen CE, Williams D, Underwood L, Ory, MA. Correlates of self-perceptions of spirituality in American adults. Annals of Behavioral Medicine. 2002;24(1):59-68.

88. Maselko J, Kubzansky LD. Gender differences in religious practices, spiritual experiences and health: Results from the US General Social Survey. Social Science \& Medicine 2006;62(11):2848-60.
89. Son J, Lin N, George LK.Cross-national comparison of social support structures between Taiwan and the United States.J Health Soc Behav. 2008;49(1):104-18.

90. Plant EA, Sachs-Ericsson N.Racial and ethnic differences in depression: the roles of social support and meeting basic needs. J Consult Clin Psychol. 2004;72(1):41-52.

91. Christian MD, Barbarin OA. Cultural resources and psychological adjustment of African American children: Effects of spirituality and racial attribution. Journal of Black Psychology. 2001;27(1):43-63.

92. Jagers RJ, Mock LO. Cultural and social outcomes among inner-city African American children: An Afrographic exploration. Journal of Black Psychology. 1993;19(4):1353-61

93. Coles R. The Spiritual Life of Children. Boston: Houghton Mifflin Co.; 1990.

94. Lincoln KD, Chatters LM, Taylor RJ. Psychological distress among black and white Americans: differential effects of social support, negative interaction and personal control. J Health Soc Behav. 2003;44(3):390-407.

95. Biegel DE, Magaziner J, Baum M. Social support networks of white and black elderly people at risk for institutionalization. Health Soc Work. 1991;16(4):245-57.

96. Mendes de Leon CF, Gold DT, Glass TA, Kaplan L, George LK. Disability as a function of social networks and support in elderly African Americans and Whites: the Duke EPESE 1986--1992. J Gerontol B Psychol Sci Soc Sci. 2001;56(3):S179-90.

97. Jones JM. Exposure to chronic community violence: Resilience in African American children. Journal of Black Psychology. 2007;33(2):125-49.

98. Haight WL. African American Children at Church: A sociocultural perspective. New York: Cambridge University Press; 2002.

99. Garbarino J, Bedard C. Spiritual challenges to children facing violent trauma. Childhood: A Global Journal of Child Research. 1996;3(4):467-78.

100.Littlejohn-Blake SM, Darling CA. Understanding the strengths of African American families. Journal of Black Studies. 1993;23(4):46071.

101.Individual and community responses to disasters. In: Ursano RJ, Fullerton CS, Weisaeth L, Raphael B, editors. Textbook of disaster psychiatry. Cambridge: Cambridge University Press. 2007:3-26.

102.Institute of Medicine. Preparing for the psychological consequences of terrorism: A public health strategy. Available: http://www.nap.edu/catalog.php?record_id=10717. 2003. Accessed 29 February 2008.

103.Ursano RJ, Fullerton CS, Weisaeth L, Raphael B, editors. Public health and disaster mental health: Preparing, responding and recovering. Textbook of disaster psychiatry. Cambridge: Cambridge University Press.2007; 311-326.

104.Thorpe LE, Assari S, Deppen S, Glied S, Lurie N, Mauer MP, Mays VM, Trapido E. The role of epidemiology in disaster response policy development. Ann Epidemiol. 2014: S1047-2797(14)00318-4.

105. Bolton P, Bass J, Betancourt T, Speelman L, On- yango G, Clougherty KF, Neugebauer R, Murray L, Verdeli H; Interventions for Depression Symptoms Among Adolescent Survivors of War and Displacement in Northern Uganda: A Randomized Controlled Trial. JAMA. 2007;298(5):519-27.

106.World Health Organization. World health report 2001 - Mental health: new understanding, new hope. Geneva: Switzerland; 2001.

107. Yarvis JS. A civilian social worker's guide to the treatment of warinduced PTSD. Soc Work Health Care. 2011;50(1):51-72.

108. Benedek DM, Ursano RJ. Exposure to War as a Risk Factor for Mental Disorders. PLoS Med. 2008;5(4):e82.

109. Scholte WF, Olff M, Ventevogel P, de Vries GJ, Jansveld E, Cardozo BL, Crawford CA. Mental health symptoms following war and repression in eastern Afghanistan. JAMA. 2004;292(5):585-93.

110.Karam EG, Mneimneh ZN, Dimassi H, Fayyad JA, Karam AN, et al. Lifetime prevalence of mental disorders in Lebanon: First onset, treatment, and exposure to war. PloS. 2008;Med 5(4): e61.

111.UN. Hundreds of thousands of Syrian Kurds live in fear of Islamist extremist violence. Available at: http://www.un.org/apps/news/story.asp?NewsID=48799\#.VXLGIL5FaY

112.Hiltermann JR. A Poisonous Affair: America, Iraq, and the Gassing of Halabja. New York, NY: Cambridge University Press; 2007. Available at: http://www.ohchr.org/EN/NewsEvents/Pages/SyriaSieges.aspx

113.Dejman M, Forouzan AS, Assari S, Rasoulian M, Jazayery A, Malekafzali H, BaradaranEftekhari M, Falahat K, Ekblad S. How Iranian lay people in three ethnic groups conceptualize a case of a depressed woman: an explanatory model. Ethn Health. 2010;15(5):475-93.

114.Kurdish population. Available at: http://en.wikipedia.org/wiki/Kurdish_population 
115.Encyclopaedia. Iran, Ethnic groups. Encyclopaedia Britannica. [updated March ,17 2007; cited 2007 March,17]; Available from: www.britannica.com/eb/article- 230041/Iran. 52. 2007.

116.Mofidi N, Ghazinour M, Salander-Renberg E, Richter Jr. Attitudes towards suicide among Kurdish people in Iran. Social Psychiatry Psychiatric Epidemiology. 2008;43:291-98.

117.Hashemian F, Khoshnood K, Desai MM, Falahati F, Kasl S, Southwick S. Anxiety, Depression, and Posttraumatic Stress in Iranian Survivors of Chemical Warfare. The Journal of the American Medical Association. 2006;296(5):560-66

118. Khateri S, Ghanei M, Keshavarz S, Soroush M, Haines D. Incidence of lung, eye, and skin lesions as late complications in 34,000 Iranians with wartime exposure to mustard agent. J Occup Environ Med Am Coll Occup Environ Med. 2003;45(11):1136-43.

119.O'Leary CA. The Kurds of Iraq: Recent history, future prospects. Middle East Review of International Affairs. 2002 6:1-14

120.Rogg I, Rimscha H. The Kurds as parties to and victims of conflicts in Iraq. Int Rev Red Cross. 2007;89(868):823-42.

121. Stover E, Sissons M, Pham P, Vinck P. Justice on hold: accountability and social reconstruction in Iraq. Int Rev Red Cross. 2008;90(869):5-28.

122.Iraq's Kurdistan in Therapy. Availaable at: http://pulitzercenter.org/reporting/middle-east-iraq-kurdistan-isil-ptsd-mentalhealth

123.Makiya K. Republic of Fear: The Politics of Modern Iraq. University of California Press; Berkeley and Los Angeles, California, USA, 1998

124.Iraqi Kurdistan's Ministry of Culture. Al Anfal Operations and its effects on young people. Ministry of Culture, Iraqi Kurdistan: Erbil, Iraqi Kurdistan, 2009

125.Cummings S, Sull L, Davis C, Worley N. Correlates of depression among older Kurdish refugees. Soc Work. 2011;56(2):159-68.

126.Othman N. Suicide by self-burning in Iraqi Kurdistan: description and risk factors. Arch Suicide Res. 2011:15(3):238-49.

127.Razaeian M, Sharifirad G. Case fatality rates of different suicide methods within Ilam province of Iran. J Educ Health Promot. 2012;1:44.

128.Canetto SS, Sakinofsky I. The gender paradox in suicide. Suicide Life Threat Behav. 1998;28(1):1-23.

129.Tsirigotis K, Gruszczynski W, Tsirigotis M. Gender differentiation in methods of suicide attempts. Med Sci Monit. 2011:17(8):PH65-70.

130.Kupferschmid S, Gysin-Maillart A, Bühler SK, Steffen T, Michel K, Schimmelmann BG, Reisch T. Gender differences in methods of suicide attempts and prevalence of previous suicide attempts. Z Kinder Jugendpsychiatr Psychother. 2013;41(6):401-5.

131.Othman N, Kendrick D. Burns in Sulaymaniyah province, Iraq: epidemiology and risk factors for death in patients admitted to hospital. J Burn Care Res. 2011;32(4):e126-34.

132.Kiadaliri, Aliasghar A, et al. Overall, gender and social inequalities in suicide mortality in Iran, 2006-2010: a time trend province-level study. BMJ open 4.8 2014: e005227.

133.Janghorbani M, Sharifirad GR. Completed and attempted suicide in Ilam, Iran (1995-2002): incidence and associated factors. Archives of Iranian Medicine 2005.

134.Behmanehsh Pour F; Tabatabaei SM; Bakhshani NM, Epidemiology of Suicide and its Associated Socio-demographic Factors in Patients Admitted to Emergency Department of ZahedanKhatam-Al-Anbia Hospital. Int J High Risk Behav Addict. 2014;3(4):e22637.

135.Dejman M, Cultural Explanatory Model of Depression among Iranian Women in Three Ethnic Groups. (Fars, Kurds and Turks). Institutionen för klinisk neurovetenskap/Department of Clinical Neuroscience, 2010.

136.Heartland Alliance. Iraq: Support for Survivors of Torture and Trauma. Available at: http://www.heartlandalliance.org/international/wherewework/project-pages/iraq-victims-violence.html

137.Bolton P, Bass JK, Zangana G, Kamal T, Murray S, Kaysen D, Lejuez CW, Lindgren K, Pagoto S, Murray LK, Van Wyk S, Ahmed A, Mohammad Amin NM, Rosenblum M. A randomized controlled trial of mental health interventions for survivors of systematic violence in Kurdistan, Northern Iraq. BMC Psychiatry. 2014;14(1):1693.

138.Faulk KE, Gloria CT, Steinhardt MA. Coping profiles characterize individual flourishing, languishing, and depression. Anxiety Stress Coping. 2013;26(4):378-90

139.Fosha D. Positive affects and the transformation of suffering into flourishing. Ann N Y Acad Sci. 2009;1172:252-62.

140.Conrad CD. Chronic stress-induced hippocampal vulnerability: the glucocorticoid vulnerability hypothesis. Rev Neurosci. 2008;19(6):395-411.

141.Palgi Y, Ben-Ezra M, Shrira A. The effect of prolonged exposure to war-related stress among hospital personnel with different affect types: lessons from the Second Lebanon War and the Gaza "Cast Lead" operation. Eur J Psychotraumatol. 2012; 3: 10.3402/ejpt.v3i0.7165.

142.Marshal MP, Dietz LJ, Friedman MS, Stall R, Smith HA, McGinley J, Thoma BC, Murray PJ, D'Augelli AR, Brent DA. Suicidality and depression disparities between sexual minority and heterosexual youth: a meta-analytic review. J Adolesc Health. 2011;49(2):115-23.

143.Ahmed K, Bhugra D. Depression across ethnic minority cultures: diagnostic issues. World Cult Psychiatr Res Rev. 2007;2:47-56.

144.Alegría M, Chatterji P, Wells K, Cao Z, Chen CN, Takeuchi D, Jackson J, Meng XL. Disparity in depression treatment among racial and ethnic minority populations in the United States.Psychiatr Serv. 2008;59(11):1264-72.

145.Dejman M, Forouzan A, Assari S, Malekafzali H, Nohesara Sh, Khatibzadeh N, Falahat K, Ekblad S. An Explanatory Model of Depression among Female Patients in Fars, Kurds, Turks Ethnic Groups of Iran.Iran J Public Health. 2011;40(3):79-88.

146.Dejman M, Forouzan A, Assari S, Farahani M, MalekAfzali H, Rostami M, et al. Clinicians' View of Experience of Assessing and Following Up Depression among Women in IR Iran. WCPRR. 2009;4(2):74-88.

147.Ault-Brutus AA. Changes in racial-ethnic disparities in use and adequacy of mental health care in the United States, 1990-2003. Psychiatr Serv. 2012;63(6):531-40. 